\title{
Is Metformin a Safe and Effective Treatment of Gestational Diabetes Mellitus?
}

\author{
Clelia Callegari ${ }^{1 *}$, Paola Algeri ${ }^{1}$, Isabella Crippa ${ }^{1}$, Eloisa Mariani ${ }^{1}$, Serena Mussi $^{2}$, Irene Cameroni ${ }^{1}$, Cristina \\ Plevani $^{3}$, Nadia Roncaglia ${ }^{1}$ and Patrizia Vergani ${ }^{1}$
}

${ }^{1}$ Department of Obstetrics and Gynecology, University of Milano Bicocca, Italy

${ }^{2}$ Carate Hospital, Italy

${ }^{3}$ Lecco Hospital, Italy

Submission: January 16, 2018; Published: March 09, 2018

*Corresponding author: Clelia Callegari, Department of Obstetrics and Gynecology, MBBM Foundation, San Gerardo Hospital; University of Milano Bicocca, Monza, Italy, Email: clelia.callegari@gmail.com

\begin{abstract}
Background: Gestational diabetes mellitus (GDM) is associated with maternal and fetal/neonatal complications related to maternal hyperglycemia, which could be reduced thanks to an optimal glycemic control. The aim of our study was to evaluate maternal and neonatal outcomes in a cohort of women with GDM, in order to demonstrate metformin's safety and efficacy.

Methods: We conducted a retrospective study of all women with GDM delivered in MBBM Foundation, San Gerardo Hospital, between 01/2009 and 06/2012, comparing pregnancy course and neonatal outcomes in women in diet to those treated with metformin. Exclusion criteria were multiple gestations and pregestational diabetes.

Results: 763 patients were divided in 2 groups according to therapy: 593(78\%) in diet group and $170(22 \%)$ in metformin one; $8(5 \%)$ of the latter group needed insulin addiction to control the disease. Preeclampsia and hypotiroidism were more frequent in metformin group, but the higher rate of preeclampsia was correlated only to chronic hypertension at the logistic regression analysis. Delivery mode was similar between the study groups, even if induction of labor was more frequent and gestational age at delivery was lower in the metformin group compared to diet one. At the logistic regression, an higher pre-gestational BMI and a lower GA at diagnosis resulted independent predictors of use of metformin. Considering neonatal outcomes, in diet group birth weight and gestational age at delivery were greater; considering rate of birth weight $>4000$, of small and large for gestational age there were no difference. Jaundice occurred more frequently in metformin group, while for other adverse neonatal outcomes no statistical differences were found between the groups. At the multivariate analysis, hyperbilirubinemia resulted independently related to the earlier gestational age at delivery and not to the use of metformin.

Conclusion: Metformin can be a safe and effective pharmacological treatment for GDM in case of uncontrolled glycaemia with diet alone; although metformin is used in patients with a more severe form of GDM, it allows to obtain maternal and perinatal outcomes similar to patients with easier-to-treat GDM, requiring only diet.
\end{abstract}

\section{Introduction}

Gestational Diabetes Mellitus (GDM) affects approximately $5-7 \%$ of all pregnancies [1-3]. Its prevalence reported a significant increase in several ethnicity groups during the past 20 years, due to older maternal age and higher rate of obesity and sedentary lifestyle.

Maternal and perinatal complications related to maternal hyperglycemia are Cesarean Section (CS), pregnancy induced hypertension, excessive fetal growth, leading to large for

gestational age infants or macrosomia and a subsequent higher risk of shoulder dystocia, birth injuries and stillbirth [4-6]. An adequate glycaemic control is necessary to reduce the incidence of these adverse pregnancy outcomes [2]. The glycaemic targets were traditionally achieved by insulin therapy, which had been considered the standard practice for women with GDM who could not have been controlled by diet and physical activity. However, this treatment, due to requirement of multiple daily injections and the risk of hypoglycaemia, could be difficult to manage for 


\section{Current Research in Diabetes \& Obesity Journal}

pregnant women who were not wont to use it [7]. Consequently, also to reduce the therapy cost, oral hypoglycaemic agent (i.e. metformin or glyburide) might be an advantageous alternative.

Glyburide is a second-generation sulphanylurea. It increases insulin secretion and insulin sensitivity of peripheral tissues. Metformin, a biguanide agent, inhibits hepatic gluconeogenesis and glucose absorption and stimulates glucose uptake in peripheral tissues. Metformin is associated with a lower risk of hypoglycemia and weight gain than insulin [7-11]. Few randomized studies showed that main maternal and short-term neonatal outcomes did not differ significantly between insulin and oral antidiabetic medication [7,11,12] Both glyburide and metformin cross the placenta: potential effects regarding fetal-neonatal metabolism are relatively understudied, in consideration of this issue, their use is still limitated in pregnancy.

A recently published study retracing metformin history underline its role in reducing preeclampsia and gestational hypertension [13]. The aim of our study was to evaluate maternal and neonatal outcomes in a cohort of women with GDM, in order to demonstrate metformin's safety and efficacy.

\section{Methods}

We conducted a retrospective study, which included all singleton pregnancies complicated by GDM (diagnosis was made according to NDDG guidelines until March 2010 and to IADPSG recommendations subsequently) [14,15] delivered at the Department of Maternal-Fetal Medicine, MBBM Foundation, University of Milano Bicocca, Monza, between January 2009 and June 2012. Exclusion criteria were multiple gestations and pregestational diabetes. The aim of this study was to evaluate pregnancy course and neonatal outcomes in women in diet compared to those treated with metformin.

In our Institution, we performed a screening for GDM only in risk patients. Specifically, women with high risk factors (one among previous GDM, body mass index over 29, or basal hyperglycemia pre-pregnancy or during the first trimester) were tested with glycaemic curve (75 grams of glucose) at 1618 weeks and, if negative, retested at 24-28 weeks. Patients with mild risk factors (one among maternal age over 34 years, body mass index over 24 , previous macrosomia, familiarity for diabetes, nationality with high prevalence of diabetes) were TESTED at 24-28 weeks. If polyhydramnios or macrosomia were detected, the glycaemic curve was prescribed. In case of positive curve or basal glycaemia over $126 \mathrm{mg} / \mathrm{dl}$, random glycaemia over $200 \mathrm{mg} / \mathrm{dl}$ or glycated hemoglobin over $6.5 \%$, GDM was diagnosed [16]. Pregnant women with this complication were counseled and first treated with diet. Self blood glucose monitoring was prescribed. After two weeks of diet, if glycaemic control was poor, metformin was started (starting from 500mg daily and eventually progressively increased, considering glycaemic control, to a maximum dosage of $2500 \mathrm{mg}$ ). If, despite therapy, an optimal glycaemic control was not reached, insulin analogues were added. Obstetrical visits were planned, according to severity of the disease.

Delivery was planned, with induction of labor, at 41 weeks in women in diet, and between 38-39 weeks in case of pharmacological therapy. Data were collected from reviewing patients' records and added in a dedicated database by a referred fellow, with periodical control by a senior consultant. The study was exempted from Institutional Review Board approval because it involved existing data and individual identifiers were removed. All variables were evaluated using Student Test or one-way analysis of variance (ANOVA) for continuous variables, and Chisquare or Fisher's exact test for categorical variables. Logistic regression analysis was performed to identify independent predictors of adverse outcome. A two-tailed $\mathrm{p}<0.05$ or an odds ratio (OR) with $95 \%$ confidence interval (CI) not inclusive of the unity was considered significant. SPSS version 20 was used for all statistical calculation.

\section{Results}

Table 1: Demographic characteristics of the study population.

\begin{tabular}{|c|c|c|c|}
\hline & $\begin{array}{c}\text { Diet } \\
(\mathbf{N = 5 9 3 )}\end{array}$ & $\begin{array}{c}\text { Metformin } \\
\mathbf{( N = 1 7 0 )}\end{array}$ & p Value \\
\hline Maternal Age & $33.3 \pm 5.3$ & $33.7 \pm 5.4$ & 0.364 \\
\hline Nulliparity & $331(55.8 \%)$ & $81(47.7 \%)$ & 0.067 \\
\hline $\begin{array}{c}\text { Average pre- } \\
\text { gestational BMI }\end{array}$ & $25.6 \pm 5.3$ & $29.1 \pm 6.2$ & $<0.001$ \\
\hline $\begin{array}{c}\text { Pre-gestational BMI } \\
>30\end{array}$ & $86(14.5 \%)$ & $60(35.3 \%)$ & $<0.001$ \\
\hline $\begin{array}{c}\text { GA at diagnosis } \\
\text { (weeks) }\end{array}$ & $28.2 \pm 5.0$ & $25.3 \pm 6.0$ & $<0.001$ \\
\hline Caucasian ethnicity & $455(76.7 \%)$ & $93(54.7 \%)$ & $<0.001$ \\
\hline Asian ethnicity & $63(10.6 \%)$ & $30(17.7 \%)$ & 0.017 \\
\hline Arab ethnicity & $46(7.8 \%)$ & $35(20.6 \%)$ & $<0.001$ \\
\hline Chronic Hypertension & $15(2.5 \%)$ & $13(7.7 \%)$ & 0.004 \\
\hline
\end{tabular}

Note: BMI: Body Mass Index; GA: Gestational Age

The study population includes 763 patients divided into $78 \%$ in diet group and $22 \%$ in metformin one (8 of these $(5 \%)$ needed insulin addiction to control the disease). The metformin group showed a pre-gestational Body Mass Index (BMI), an obesity rate, and a prevalence of chronic hypertension higher compared to diet group, while the gestational age at diagnosis was lower. Arab and Asiatic ethnicities were more represented in metformin group (Table 1). A higher number of pregnancies was complicated by preeclampsia and hypotiroidism in metformin group. Delivery mode was similar between the study groups, even if induction of labor was more frequent in metformin group compared to diet one. The gestational age at delivery was lower in the metformin group (Table 2). At the logistic regression, an higher pre-gestational BMI $(\mathrm{p}<0.001)$ and a lower GA at 


\section{Current Research in Diabetes \& Obesity Journal}

diagnosis $(\mathrm{p}<0.001)$ resulted independent predictors of use of metformin. Instead Caucasian ethnicity was a protective factor $(\mathrm{p}<0.001)$.

Table 2: Characteristics of pregnancy and delivery.

\begin{tabular}{|c|c|c|c|}
\hline & $\begin{array}{c}\text { Diet } \\
(\mathbf{N = 5 9 3 )}\end{array}$ & $\begin{array}{c}\text { Metformin } \\
(\mathbf{N = 1 7 0 )}\end{array}$ & p Value \\
\hline Cholestasis & $18(3.0 \%)$ & $4(2.4 \%)$ & 0.798 \\
\hline Preeclampsia & $11(1.9 \%)$ & $11(6.5 \%)$ & 0.003 \\
\hline Hypotiroidism & $63(10.6 \%)$ & $35(20.6 \%)$ & $<0.001$ \\
\hline Intrauterine Fetal Demise & $1(0.2 \%)$ & 0 & 1.000 \\
\hline GA at delivery & $39.0 \pm 2.0$ & $38.0 \pm 1.2$ & $<0.001$ \\
\hline Preterm delivery <34 ws & $9(1.5 \%)$ & $2(1.2 \%)$ & 1.000 \\
\hline Preterm delivery <37 ws & $40(6.8 \%)$ & $16(9.4 \%)$ & 0.245 \\
\hline Induction of labor & $239(44.7 \%)$ & $116(79.5 \%)$ & $<0.001$ \\
\hline Vaginal delivery & $482(81.3 \%)$ & $134(78.8 \%)$ & 0.508 \\
\hline CS & $111(18.7 \%)$ & $36(21.2 \%)$ & 0.508 \\
\hline Elective CS & $58(52.3 \%)$ & $34(66.7 \%)$ & 0.176 \\
\hline CS in labour & $53(47.7 \%)$ & $12(33.3 \%)$ & 0.176 \\
\hline
\end{tabular}

Note: GA: Gestational Age; CS: Cesarean Section

Table 3: Neonatal outcomes.

\begin{tabular}{|c|c|c|c|}
\hline & $\begin{array}{c}\text { Diet } \\
(\mathbf{N = 5 9 3 )}\end{array}$ & $\begin{array}{c}\text { Metformin } \\
(\mathbf{N = 1 7 0 )}\end{array}$ & p Value \\
\hline Birth Weight (g) & $3255 \pm 513$ & $3166 \pm 523$ & 0.049 \\
\hline Macrosomia (>4000g ) & $34(5.7 \%)$ & $4(2.4 \%)$ & 0.107 \\
\hline LGA & $33(5.6 \%)$ & $14(8.2 \%)$ & 0.208 \\
\hline SGA & $23(3.9 \%)$ & $7(4.1 \%)$ & 0.825 \\
\hline Apgar 5 min $<7$ & $9(1.5 \%)$ & $3(1.8 \%)$ & 0.735 \\
\hline pH <7.10 & $14(2.4 \%)$ & $1(0.6 \%)$ & 0.211 \\
\hline NICU admission & $41(7.0 \%)$ & $9(5.3 \%)$ & 0.598 \\
\hline Jaundice & $83(14.1 \%)$ & $42(24.7 \%)$ & 0.001 \\
\hline Hypoglycemia & $13(2.2 \%)$ & $3(1.8 \%)$ & 1.000 \\
\hline Shoulder Dystocia & $2(0.3 \%)$ & - & 1.000 \\
\hline Neonatal fractures & $1(0.2 \%)$ & $1(0.6 \%)$ & 0.397 \\
\hline RDS & $14(2.4 \%)$ & $3(1.8 \%)$ & 0.776 \\
\hline
\end{tabular}

Note: LGA: Large for Gestational Age; SGA: Small for Gestational Age; NICU: Neonatal Intensive Care Unit; RDS: Respiratory Distress Syndrome

In light of the higher rate of preeclampsia in metformin group and in consideration of the import of this complication, that could correlate to adverse maternal and fetal outcome, we analyzed which factors correlated to its development; at the analysis only chronic hypertension resulted a risk factor ( $p$ <0.001). Neonatal outcomes are reported in Table 3: in diet group birth weight and gestational age at delivery were greater; considering rate of birth weight $>4000 \mathrm{~g}$ and rate of small (SGA) and large for gestational age (LGA) there was no difference. Concerning adverse outcomes, we found no statistical differences between the groups, except for rate of jaundice: in metformin group it occurred with a higher frequency. At the multivariate analysis, hyperbilirubinemia resulted independently related to the earlier gestational age at delivery $(p<0.001)$ and not to the use of metformin ( $p=0.831)$.

\section{Discussion}

Our population included a large number of patients, of which $22 \%$ was treated with metformin, only in $5 \%$ additional insulin therapy was required. Our rate of metformin failure is lower compared to those reported in previous studies $(10.2 \%$ [17], 14\% [18] and 46.3\% [10]). In our population, all patient appreciated the oral intake and none of the women discontinued the metformin use due to side effects. Our study showed as metformin treatment, compared to diet, was safe in pregnancies complicated by GDM, without an increment of adverse maternal outcomes. The demographic characteristics, reported in the Table 1, showed that in metformin group the rate of obesity and the presence of comorbidity were more higher. It is known that elevate BMI and pre-gestational chronic disease could be associated to the development of a more severe GDM, requiring pharmacological intervention. Consequently, patients with more severe GDM received metformin, whereas women with less severe GDM were treated with diet only; despite this, maternal outcomes were similar in both groups in our study.

Is known that GDM correlates with maternal and neonatal adverse outcomes [4-6]. Specifically, in literature, a retrospective study, analyzing 118 women with GDM treated with oral antidiabetic drug vs insulin, correlated metformin use to preeclampsia development [19]. In our population we found a higher rate of preeclampsia in metformin group, but this result was not related to the use of the drug, but only to the presence of chronic hypertension. Our population was different from the one reported by Hellmuth and colleagues, considering that we compared metformin to diet and not metformin to insulin. Other studies that have considered the development of preeclampsia in GDM population treated with metformin did not find any correlation between the drug and this complication $[10,17,20]$. Concerning development of polyhydramnios and fetal macrosomia (indirect signs of not controlled GDM), we did not find any differences in the two groups. In our opinion this is the result of the efficacy of metformin in controlling glycemia and reducing the development of its complications. The necessity of an accurate delivery timing is reported to be useful to reduce the risk of intrauterine fetal demise and excessive fetal growth. In contrast induction of labor is associated with an increase of cesarean section and iatrogenic prematurity. To reduce both risk we induced the labor at 38-39 weeks in case of metformin use, fetal macrosomia and polyhydramnios development, and at 41 weeks in patients in diet therapy. Even if the rate of induction in metformin group was almost twice respect those of the diet 
group, cesarean section frequency was similar between the two groups. This is probably due to the choice of induction at higher gestational age, over the late prematurity; despite our management, we did not register an increased incidence of endo-uterine demise (in our population, we reported one case in diet group).

Even if, in metformin treated women, we perform the induction of labor at higher gestational age (over the late prematurity), in this population the rate of jaundice was duplicated compared to the diet treated mothers (Table 3). At logistic regression, this outcome was related only to the earlier gestational age at delivery of these infants and not to the use of metformin. In our population, metformin was able to contrast a more severe disease, reducing the incidence of other adverse neonatal outcomes; specifically babies born from mother with severe disease, treated with pharmacological therapy, had the same growth outcomes of those with milder disease. Moreover we did not find any difference in rate of hypoglycemia, Respiratory Distress Syndrome (RDS) and Neonatal Intensive Care Unit (NICU) admission frequency.

Even if insulin is proven to be safe and effective in pregnancy and it is considered the gold standard therapy for GDM, considering our results we can support that metformin is a valid alternative in case of difficult glycaemic control. Furthermore, in a large sample size population, we found that the metformin use was not correlated to maternal, delivery and short term neonatal adverse outcomes. In addition, all pregnant women continued with therapy until the delivery, in fact we reported no severe adverse effects correlated to metformin use and patients appreciated the oral intake of this drug. The limits of our study are its retrospective nature and the lack of neonatal follow up to evaluate long-term effect of metformin use. Another limit of our analysis is that international criteria for GDM diagnosis changed during the study period $[15,16]$.

\section{Conclusion}

Metformin can be a safe and effective pharmacological treatment for GDM in case of uncontrolled glycaemia with diet alone; although metformin is used in patients with a more severe form of GDM, it allowed to obtain maternal and perinatal outcomes similar to patients with easier-to-treat GDM, requiring only diet $[21,22]$.

\section{References}

1. Whitelaw B, Gayle C, Hunt KF (2011) Gestational diabetes. Obstetrics, Gynaecology and Reproductive Medicine 24(8): 238-244.

2. (2011) Diagnosis and treatment of gestational diabetes. Royal College of Obstetricians \& Gynaecologists, pp. 1-6.

3. American Diabetes Association (2013) Diagnosis and classification of diabetes mellitus. Diabetes Care 36 Suppl 1: S62-S69.

4. Yogev Y, Xenakis E, Langer O (2004) The relation between preeclampsia and the severity of gestational diabetes. Am J Obstet Gynecol 191(5): 1655-1660.
5. Metzger BE, Lowe LP, Dyer AR, Trimble ER, Chaovarindr U, et al. (2008) Hyperglycemia and adverse pregnancy outcomes. N Engl J Med 358(19): 1991-2002.

6. Landon MB, Spong CY, Thom E, Carpenter MW, Ramin SM, et al. (2009) A multicenter, randomized trial of treatment for mild gestational diabetes. N Engl J Med 361(14): 1339-1348.

7. Nicholson W, Baptiste Roberts K (2011) Oral hypoglycaemic agents during pregnancy: the evidence for effectiveness and safety. Best Pract Res Clin Obstet Gynaecol 25(1): 51-63.

8. (2001) ACOG Practice Bulletin. Clinical management guidelines for obstetrician-gynecologists. Gestational Diabetes Mellitus. Obstet Gynecol 98(3): 525-538.

9. National Collaborating Centre for Women's and Children's Health (2008) Diabetes in pregnancy: management of diabetes and its complications from preconception to the postnatal period.

10. Rowan JA, Hague WM, Gao W, Battin MR, Moore MP (2008) Metformin versus insulin for the treatment of gestational diabetes. New Engl J Med 358(19): 2003-2015.

11. Moore LE, Briery C, Clokey D, Martin RW, Williford NJ, et al. (2007) Metformin and insulin in the management of gestational diabetes: preliminare results of a comparison. J Reprod Med 52(11): 1011-1015.

12. Rowan JA, Rush EC, Obolonkin V, Battin M, Wouldes T, et al. (2011) Metformin in Gestational Diabetes: The Offspring Follow-Up (MiG TOFU): Body Composition at 2 Years of Age. Diabetes Care 34(10): 2279-2284.

13. Romero R, Erez O, Hüttemann M, Maymon E, Panaitescu B, et al. (2017) Metformin, the aspirin of the $21^{\text {st }}$ century: its role in gestational diabetes mellitus, prevention of preeclampsia and cancer, and the promotion of longevity. Am J Obstet Gynecol 217(3): 282-302.

14. Carpenter MW, Coustan DR (1982) Criteria for screening tests for gestational diabetes. Am J Obstet Gynecol 144(7): 768-773.

15. Metzger BE, Gabbe SG, Persson B, Buchanan TA, Catalano PA, et al. (2010) International Association of Diabetes and Pregnancy Study Groups recommendations on the diagnosis and classification of hyperglycemia in pregnancy. Diabetes Care 33(3): 676-682.

16. (2011) Raccomandazioni Screening e diagnosi diabete gestazionale, luglio. Sistema Nazionale Linee guida- ISS (SLNG-ISS); Società Italiana Diabetologia (SID).

17. Balani J, Hyer S, Rodin D, Shehata H (2009) Pregnancy outcomes in women with gestational diabetes treated with metformin or insulin: a case-control study. Diabet Med 26(8): 798-802.

18. Niromanesh S, Alavi A, Sharbaf FR, Amjadi N, Moosavi S, et al. (2012) Metformin compared with insulin in the management of gestational diabetes mellitus: a randomized clinical trial. Diabetes Res Clin Pract 98(3): 422-429.

19. Hellmuth E, Damm P, Mølsted Pedersen L (2000) Oral Hypoglycaemic agents in 118 diabetic pregnancies. Diabet Med 17(7): 507-511.

20. Moore LE, Clokey D, Rappaport VJ, Curet LB (2010) Metformin compared with glyburide in gestational diabetes: a randomized controlled trial. Obstet Gynecol 115(1): 55-59.

21. Langer O, Conway DL, Berkus MD, Xenakis EM, Gonzalez O (2000) A comparison of glyburide and insulin in women with gestational diabetes mellitus. N Engl J Med 343(16): 1134-1138.

22. Coiner J, Rowe M, de Vente J (2014) The treatment of diabetes in pregnancy; metformin vs glyburide and insulin-biomedical evidence of fetopathy. Am J Obstet Gynecol 210(1): S148. 


\section{Current Research in Diabetes \& Obesity Journal}

This work is licensed under Creative Commons Attribution 4.0 Licens

DOI: 10.19080/CRDOJ.2018.06.555684
Your next submission with Juniper Publishers will reach you the below assets

- Quality Editorial service

- Swift Peer Review

- Reprints availability

- E-prints Service

- Manuscript Podcast for convenient understanding

- Global attainment for your research

- Manuscript accessibility in different formats

( Pdf, E-pub, Full Text, Audio)

- Unceasing customer service

Track the below URL for one-step submission https://juniperpublishers.com/online-submission.php 